\title{
Sistemas Integrados de Produção no Brasil: Situação Atual, Causas e Perspectivas
}

\author{
Adriano Proença \\ Heitor M. Caulliraux \\ Maurício Neves \\ GPI/EE-COPPE/UFRJ - Cx.Pst. 68.507 - CEP 21.945-970 - Rio de Janeiro - RJ \\ email: Adriano, Heitor, Mauricio@pep.ufrj.br
}

Palavras chave: Automação Industrial, Manufatura Integrada por Computador, Estratégia de Manufatura.

Key words: Industrial Automation; Computer Integrated Manufacturing; Manufacturing Strategy.

\section{RESUMO}

Este artigo apresenta e analisa os resultados de uma pesquisa com 260 empresas de manufatura de 10 estados brasileiros. Ele descreve sua metodologia e explora as relações entre suas caracteristicas - posição estratégica, tamanho, natureza dos processos de produção, tipo de indústria e região - e seu padrão de automação. Discute tendências e necessidades para um futuro próximo e apresenta alguns conıentários sobre o conteúdo da tecnologia adotada pelas empresas. Além disso, faz algumas considerações a respeito dos processos de modernização industrial.

\section{ABSTRACT}

This paper presents and analyzes the results of a survey of 260 manufacturing firms in 10 states in Brazil. It describes its metodology and explores the relationships between firms s characteristics - strategic positioning, size, nature of production process, industry and region-and their antomation pattern. It discusses trends and needs for the near-future and offers some remarks about the content of the tecnology adopted by the firms. It also speculates about the nature of the industry's modernization process. 


\section{PRODUÇÃO}

\section{Introdução}

Diversos observadores e analistas da evolução recente da indústria brasileira vêm constatando uma paulatina retomada dos investimentos em instalações, equipamentos e soluções informáticas. Após o ciclo de adoção de soluções de cunho fortemente organizacional e procedural, em boa parte referenciadas nas políticas do Sistema Toyota de Produção e da Gerência da Qualidade Total, as firmas manufatureiras se disporiam, agora, a migrar para soluções mais intensas em tecnologia, na forma de máquinas e sistemas informatizados, mas não integrados, de apoio à gestão.

Neste contexto, a discussão sobre o estágio da difusão de tecnologias associadas ao CIM - a Manufatura Integrada por Computador - é fundamental para situar apropriadamente o debate sobre a natureza da modernização em curso, e ultrapassar a mera constatação de que a mudança nas condições ambientais gerada pela globalização da economia brasileira na forma conduzida pela administação Cardoso obriga a empresa aqui situada a rever de forma urgente suas práticas tradicionais de condução de seu negócio e de seu sistema produtivo.

O Grupo de Produção Integrada, da Engenharia de Produção da UFRJ, em associação com o SENAI-DN, está justamente coordenando uma ampla pesquisa sobre $o$ retrato e as perspectivas do CIM no país. No momento, 260 empresas de diversos setores, em cerca de 9 estados da federação, já foram visitadas, e seus dados contabilizados em bancos de dados'. Uma publicação específica e muito abrangente com todos os resultados alcançados está sendo preparada.

Este texto especificamente aporta uma primeira análise sobre os dados agregados disponíveis, ou seja, como estão se portando as empresas diante da realidade da globalização, eminente para os próximos anos. As informações já levantadas permitiriam cruzamentos de vários tipos, com vistas à formulação de hipóteses fortes e hipóteses fracas sobre a realidade futura e presente da nossa indústria em reação a este novo contexto mundial. Neste trabalho, entretanto, optamos por expor os resultados para toda a amostra sobre dois aspectos-chave: qual o perfil de automação/informatização do parque (com considerações de setores industriais, tipo de processo produtivo e exportações) e quais as habilidades competitivas prioritárias para as empresas. Destes dados derivaremos considerações sobre a situação vigente na indústria.

\section{A Pesquisa Integração da Produção}

Por ser objeto fundamental deste texto, primeiramente iremos explicar a nossa fonte de dados, ou seja, a pesquisa "Integração da Produção". Ela foi motivada por um convênio de cooperação 
tecnológica assinado entre o Grupo de Produção Integrada, o SENAI DR/RJ e o SENAI- DN. Foi constatado que, para o desenvolvimento de qualquer trabalho na área de CIM por parte destas instituições, seria necessário um estudo de como se encontra a indústria em relação a esta tecnologia, de modo a permitir uma atuação mais precisa e orientada para a realidade brasileira.

Após uma primeira fase no estado do Rio de Janeiro, a pesquisa foi levada para outros estados do Brasil - Minas Gerais, Santa Catarina, Paraná, Rio Grande do Sul, São Paulo, Espírito Santo, Pernambuco e Bahia - seguindo sempre o mesmo modelo conceitual que será explicado posteriormente, e agregando parceiros diversos em cada região (SENAI local, Universidades, Federações das Indústrias, Governos Estaduais e Governo Federal).

\subsection{Quadro Conceitual}

O quadro conceitual que presidiu a realização da pesquisa de campo pode ser resumido na forma da seguinte figura.
Neste quadro, a automação dos sistemas de produção, seu grau de informatização e integração seguem as definições e as metas da estratégia de produção, modelo compativel com a definição de Hayes e Wheelwright (1984) para estratégia de produção. Esta, por sua vez, sustentaria a estratégia de negócio da empresa. Por fim, as orientações para formação e treinamento dos recursos humanos são definidas tanto pela estratégia de produção como pelas necessidades imediatas da automação, informatização e da integração informática. Para descrever os sistemas automatizados, informatizados e integrados utilizou-se uma variação do Modelo $Y$, desenvolvido por Scheer (1993) e que será explicado posteriormente.

\subsection{Metodologia da Pesquisa}

\subsubsection{Formação da Amostra}

Para a formação da amostra procurouse identificar empresas e gêneros industriais que se enquadravam em critérios de seleção estabelecidos. As empresas deveriam ter um total de

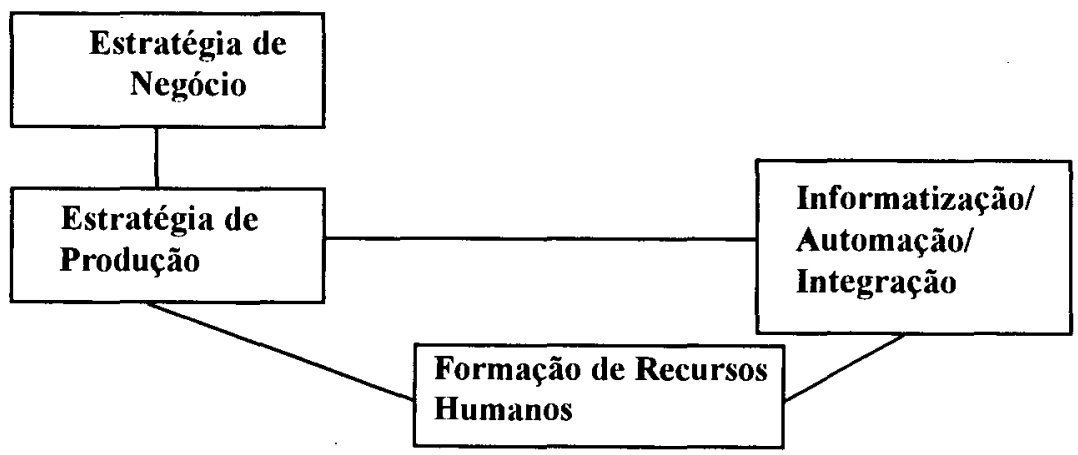

Figura 1: Quadro Conceitual da Pesquisa Integração da Produção 
empregados compreendido entre $100 \mathrm{e}$ 1000. Para esta estipulação, considerouse a adequação ao modelo CIM adotado, adiante explicado. Na seleção dos gêneros que fariam parte da amostra, foram utilizadas informações do banco de dados da RAIS, criando-se quatro diferentes critérios: importância nacional relativa, importância estadual relativa, processo de produção adequado à implantação de sistemas CIM e importância estratégica para o estado.

O primeiro diz respeito ao número de empresas que o gênero possui, em relação ao restante do país. O segundo, difere do anterior por operar com números de empregados, e utilizar como conjunto Universo os estados em questão. Para um gênero ser aceito nos dois critérios mostrados, sua média das participações relativas deve estar acima da média global. Os outros dois quesitos são complementares. O tipo de processo de produção deve ser compatível com a tecnologia CIM (neste caso, poucos gêneros foram excluidos - $p$. ex. construção civil) e, como último critério, verificam-se os gêneros que têm importância estratégica para o estado, ou seja, geravam algum interesse particular nos parceiros regionais envolvidos.

Após a análise dos quatro critérios apresentados, foram selecionados os gêneros que satisfizessem pelo menos três deles e, como resultado final, seguem dois gráficos que delimitam a amostra. Dentro de cada gênero, selecionou-se $10 \%$ do total das empresas que tinham entre 100 e 1000 empregados, por estado.

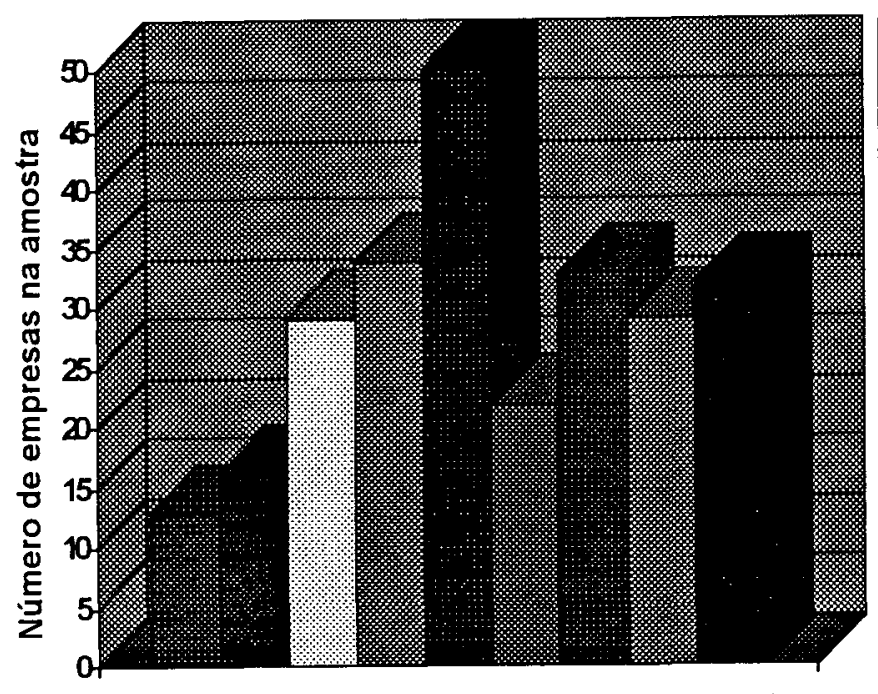

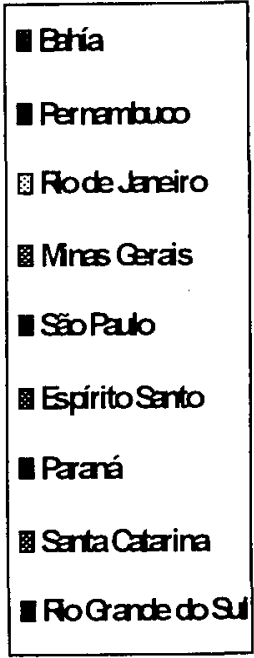

Figura 2: Amostra por estados 


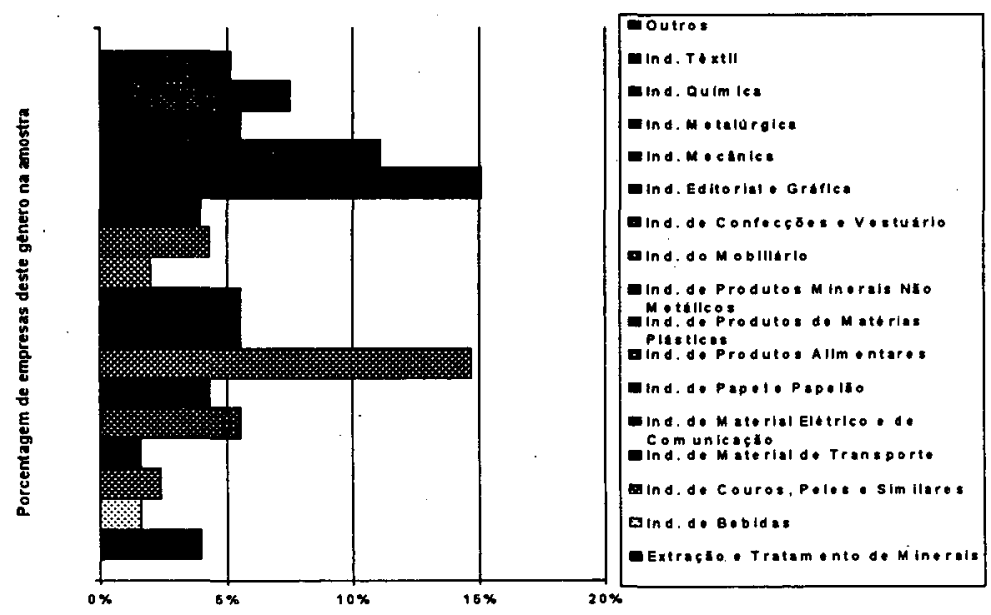

Figura 3: Amostra por Setores Industriais ${ }^{2}$

\subsubsection{Confecção dos Questionários}

Para a coleta de dados, formulou-se três questionários com assuntos diferentes, embora interligados segundo o quadro conceitual da pesquisa. São eles: dados gerais da empresa e estratégia competitiva; tecnologias de integração; recursos humanos.

O Questionário 1 (Dados da empresa e estratégia competitiva) baseou-se em tópicos referentes à identificação da empresa, principais linhas de produtos, tipo de processo de produção, característica do mercado, habilidades competitivas da empresa e análise da estratégia de produção. Esta última foi abordada por questões que enfocavam os objetivos empresariais específicos e suas ligações com a informática, ou seja, dentre cada objetivo, qual aquele que fez uso deste recurso para atingi-lo.
O Questionário 2 (Tecnologias de Integração) é aquele que poderíamos chamar de tecnológico dentro do sistema de CIM, isto é, apura dados qualitativos e quantitativos sobre hardwares e softwares, redes, automações (integradas ou não), etc. Portanto, era importante que o questionário fosse respondido por uma pessoa que tivesse visão abrangente do sistema produtivo e de toda a tecnologia que o envolve (por vezes, mais de um indivíduo). Ainda dentro deste módulo, seria necessário verificar-se a trajetória de informatização e integração da produção da empresa passo a passo, razão pela qual houve preocupação de posicionar as respostas no tempo. Pode-se com isso fazer um cronograma do que aconteceu na empresa e quais eram seus planos para o futuro. A idéia é verificar a lógica da informatização e padrão de trajetórias dentro de estratificações da amostra. 
OQuestionário 3 (Recursos Humanos) trata dos esforços realizados para atender à nova necessidade de conhecimentos advinda da modernização, ou seja, procura-se identificar treinamentos ministrados e programados, novos cargos criados, recrutamentos de pessoal especializado, tudo visto sob a ótica da automação e integração da produção.

A base de toda a pesquisa consiste no fato de terem sido os três instrumentos formulados visando uma grande interrelação entre os mesmos. Era necessário, que mesmo quando respondidos por pessoas diferentes, os questionários pudessem evidenciar ligações intrínsecas de modo que a análise do trabalho fosse um resultado por inteiro. Para atingir tal objetivo, as questões foram pensadas desde sua criação como subtemas de um mesmo contexto. A pesquisa tinha que ser integrada.

Como exemplo, cita-se a possibilidade criada no questionário 1 (estratégias) de se classificar as empresas da amostra em diferentes grupos (líderes, concorrentes ou seguidoras; empresas que exportam e que não exportam; etc.) e, com os dados do questionário 2 (tecnologias), verificar se existe algum padrão de informatização dentro de cada grupo. Fica claro aqui que busca-se não apenas levantar trajetórias de integração e automação, mas também de explicá-las através de cruzamentos diversos permitidos com as variáveis do questionário 1. Da mesma forma, a relação entre os questionários $3(\mathrm{RH})$ e o 2 (tecnologias) é muito forte, na medida em que os dados levantados referentes à necessidade de formação e treinamento de Recursos Humanos estão atados ao que foi ou será realizado neste campo tecnológico. Pode-se, portanto, analisar questões do tipo: treinam as empresas para se movimentar num eixo crescente de automação? São estes treinamentos feitos antes ou depois de introduzidas as mudanças tecnológicas? Qual o papel do SENAI e das Universidades neste cenário? Neste texto, estas questões não serão abordadas, focando-se apenas em um aspecto relativo às estratégias competitivas (a saber, habilidades competitivas mais perseguidas), e aspectos tecnológicos. Ênfase maior daremos às conclusões advindas das análises dos quadros apresentados que situarão a resposta de nossas empresas, diante da realidade de dura competição que se impõem enquanto ambiente externo.

É também importante ressaltar a forma de levantamento dos dados, estreitamente ligada aos objetivos mais amplos do projeto. Como era de nosso interesse que resultados suportassem processos de intervenção concretos, foi necessário fazer com que os dados fossem levantados através de visitas às empresas. Mais, os técnicos responsáveis pelo levantamento foram treinados de modo a garantir um entendimento homogêneo das situações encontradas. Por exemplo, um software como do Ventura cumpre a função de um CAD (ferramente informática de auxílio ao projeto do produto) em uma indústria gráfica. Este cuidado, necessário quando se deseja 
intervir concretamente, não é de praxe em muitos trabalhos realizados no pais.

\section{Resultados Selecionados da Pesquisa}

A primeira questão diz respeito à parte da pesquisa que investigou as estratégias competitivas. Um dos questionamentos buscou mapear, a partir de uma lista de habilidades competitivas ligadas a custos, flexibilidade, qualidade, tempo de entrega e serviços de pós-venda, qual era a grau de força em relação à concorrência e qual o impacto que cada um destes itens possuia no mercado para as linhas de produtos das empresas (no estilo da Manufacturing Futures Survey, como em Miller e Kim, 1991). A escala de notas variava de um a sete e, para cada vetor pesquisado (força e impacto), a análise consistiu na diferença entre as notas destes dois vetores em cada habilidade (Kim e Arnold, 1991). Repare que uma empresa com grau de força 7 (sete) em relação ao seu competidor, em uma habilidade cujo impacto possui grau 4, está com um "conforto competitivo" quantificado na diferença, ou seja, +3 (três positivo). Essa situação é diferente daquela habilidade que não tem tanta importância para a linha de produtos no mercado (por exemplo, grau 3), mas onde a empresa possui força bem inferior ao competidor (por exemplo, grau 1). Neste caso, a diferença exprime um "desconforto competitivo" de -2 (dois negativo).

Após realizadas todas as diferenças nas habilidades competitivas de todas as empresas da amostra, tirou-se uma média destes resultados que, embora não represente em grau absoluto o quanto de

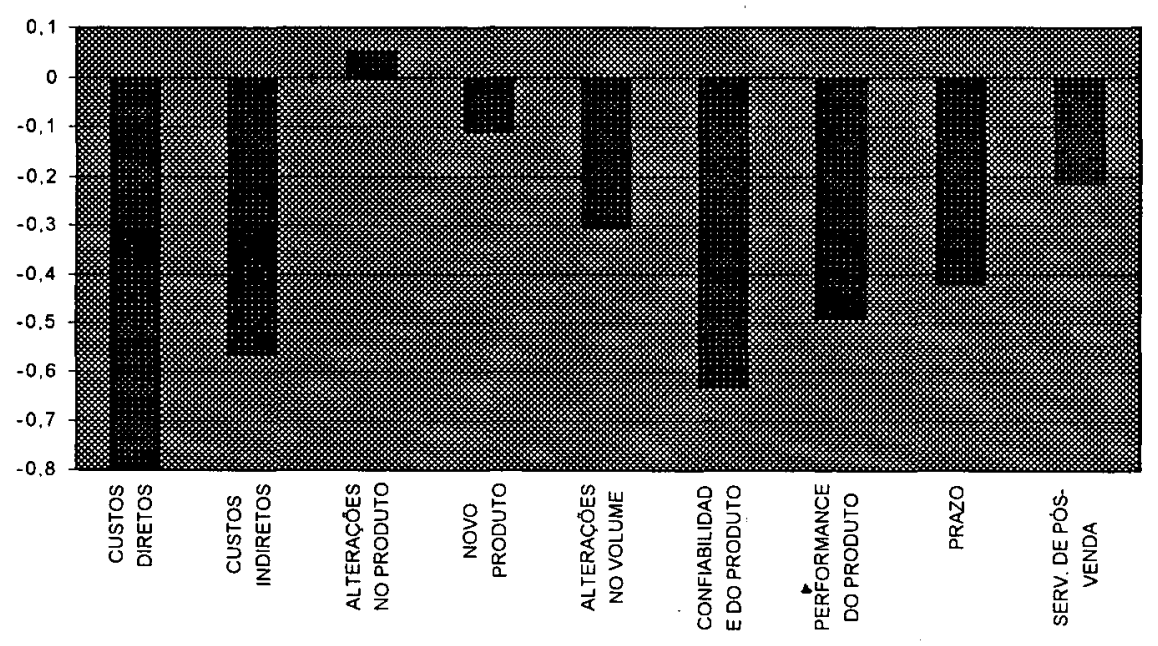

Figura 4: Posições relativas de "desconforto competitivo" 
conforto ou desconforto existe no parque fabril, serve como índice relativo para comparação entre as habilidades listadas.

Dentre todas as habilidades competitivas pesquisadas, aquelas que apresentaram os maiores índices de desconforto, na média nacional, foram as relativas a custos (diretos e indiretos) e à qualidade (confiabilidade e performance do produto). Numa primeira análise, este gráfico nos indica quais seriam as prováveis áreas prioritárias de atuação das empresas quando em busca de melhorias na sua competitividade.

$\mathrm{Na}$ área tecnológica, para descrever a informatização e automação do sistema produtivo nas empresas, utilizou-se como referência o chamado modelo Y. Desenvolvido na Universidade de Saarland, Alemanha, por Scheer (op.cit.), este modelo orientou a formulação das questões tecnológicas dos questionários da pesquisa, de modo a permitir tabulações comparáveis a referências internacionais.
Para uma melhor compreensão do modelo, deve-se inicialmente definir o que entende-se neste texto por sistema produtivo. Em nossa visão, este precisa ser conceituado de forma minimamente abrangente: produção propriamente dita (chão de fábrica), incluindo garantia de qualidade; projeto de produtos (engenharia de produtos); planejamento e controle da produção; e o planejamento de processos (engenharia industrial). $\mathrm{O}$ modelo $\mathrm{Y}$ considera todas as funções citadas, constituindo-se de dois braços: o lado direito com funções técnicas ligadas ao produto (sistemas CAE/CAD/CAM, comando numérico $(\mathrm{CN})$, planejamento do processo (CAPP), controle de equipamentos (CEquip) e controle de qualidade (CQ)); e o braço esquerdo com funções ligadas Planejamento (PP) e Controle (CP) da produção. Abaixo, segue versão incompleta do modelo apenas para exemplificação (caso o leitor queira se aprofundar na questão, sugerimos ler Caulliraux e Sales Costa, capitulo 3 (1995)).

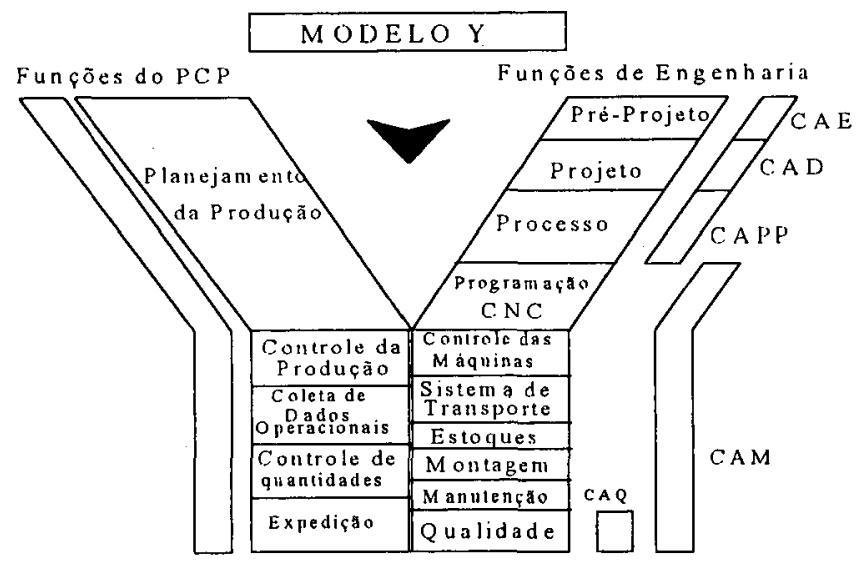

Figura 5: Modelo Y 
Portanto, na figura 6 representamos qual a porcentagem de informatização em cada função do $Y$, para o total de empresas da amostra.

A leitura do gráfico indica que a maior parte dos esforços empresariais em informatização estão ligadas à área de PCP e qualidade. Vale ressaltar que não existe aqui nenhuma espécie de corte, seja ele por processo de produção, seja por estado, seja por setor, etc., de modo que este bloco mais informatizado, que doravante denominamos de "núcleo informatizado" (PP + CP + CQ), é uma opção generalizada no cenário nacional. Para tratar das demais funções, é conveniente apresentar o gráfico que, com a mesma metodologia anterior, trabalha com a amostra dividida em empresas de processos contínuos e discretos.

Um dos pontos de destaque é a grande incidência da tecnologia CAD nas empresas de processo discreto. Por suas características, o projeto auxiliado por computador se reflete em ganho de competitividade, na medida em que pode proporcionar aumento de flexibilidade para desenhos de novos produtos ou customizações, além de, se integrado com um sistema de CAM, facilitar a elaboração de programas para as máquinas $\mathrm{CNC}$. Já as empresas de processo contínuo apresentam elevado índice de automação no controle de equipamentos, como por exemplo, uso de CLPs, SDCDs, SMCs, entre outros.

A figura 7 comprova ainda que o núcleo informatizado não é privilégio de um determinado tipo de processo; é uma constante nas empresas da amostra. Outro corte relevante para este estudo, relaciona os padrões de informatização com a tamanho das empresas, em relação ao número total de empregados.

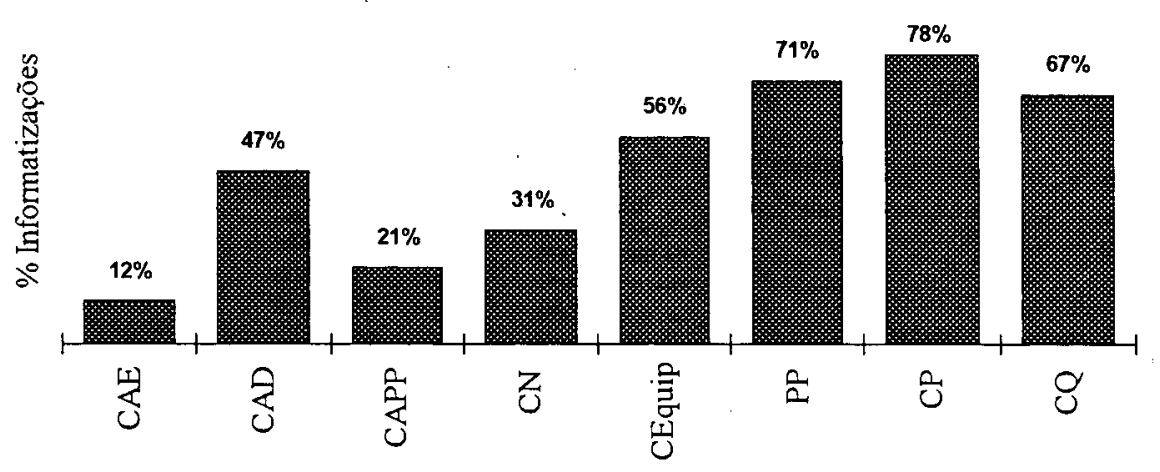

Funçōes do Modelo Y

Figura 6: Incidência de automação por função 


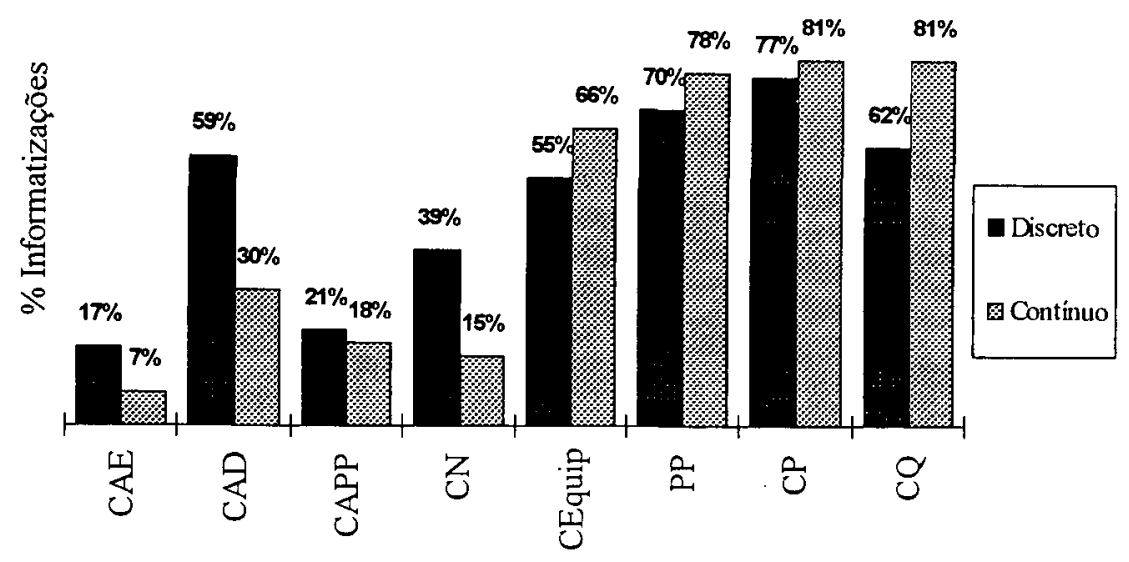

Funções do Modelo Y

Figura 7: Incidência de automação por função por tipo de processo produtivo

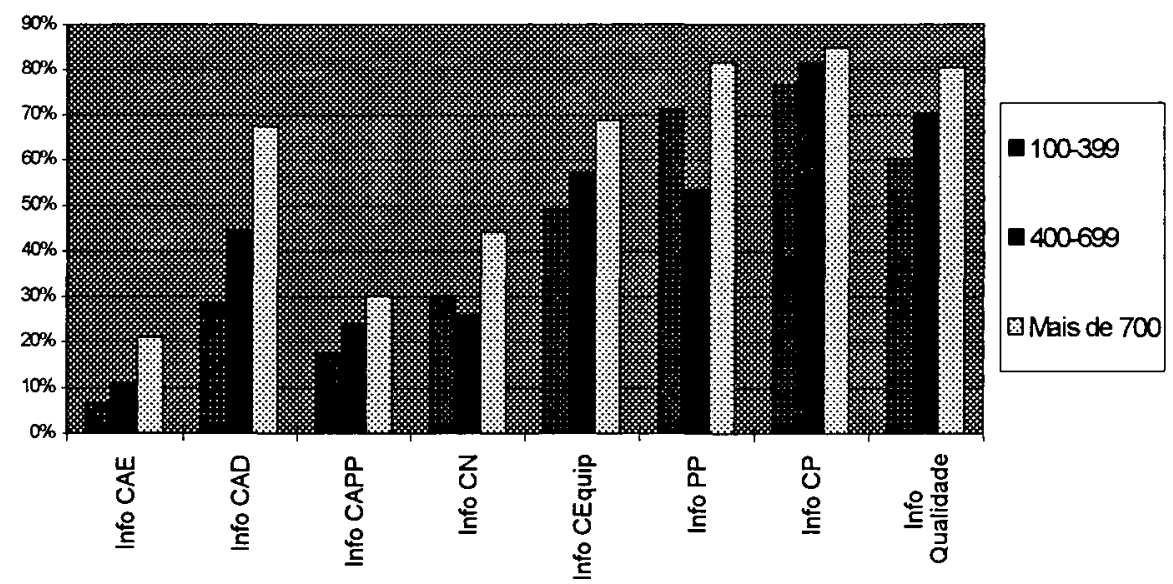

Figura 8: Incidência de automação por função por tamanho da empresa

Mais uma vez, apesar de aparecerem pequenas diferenças nos percentuais, o perfil da automação com foco no núcleo não se altera, o que demonstra ser a variável em estudo ainda não conclusiva para explicar a informatização do parque fabril.

Uma nova hipótese que pode ser testada é o fato de que as empresas 
exportadoras submetidas a um maior nível de exigência por parte de seus clientes, investem e automatizam seus processos com vistas a um aumento de competitividade. A figura 9 divide as empresas em três tipos: aquelas que não exportam; as que exportam de 1 a $5 \%$ da sua linha de produtos; as que exportam mais de $5 \%$ de sua linha.

Apesar de que existe maior informatização nas empresas exportadoras, segundo o resultado anterior, isso independe da quantidade exportada e, por vezes, constitui-se numa diferença reduzida. Além disso, temos a função de pré-projetos (CAE) mais informatizada nas empresas não exportadoras do que naquelas que exportam de 1 a $5 \%$, o que verifica que a pesquisa não pode concluir que a nossa hipótese de trabalho é conclusivamente verdadeira.
Uma outra verificação relevante diz respeito às regiões do Brasil. Existe um sentimento de que, em função do Estado de São Paulo, a região Sudeste possui maior incidência de automação do que o restante do Brasil. A figura 10 aborda esta questão.

As diferenças encontradas entre as regiões, principalmente entre Sul e Sudeste não são grandes na maior parte das funções do modelo $\mathrm{Y}$ e, no Controle de Equipamentos, a região Nordeste aparece com um índice de automação maior do que as demais regiões (o que pode ser explicado por uma maior existência de empresas de processos contínuos no parque industrial da Bahia). Portanto, uma grande discrepância regional não se verifica na pesquisa, e mais uma vez forma-se o núcleo notadamente mais informatizado, em todas as partes do Brasil.

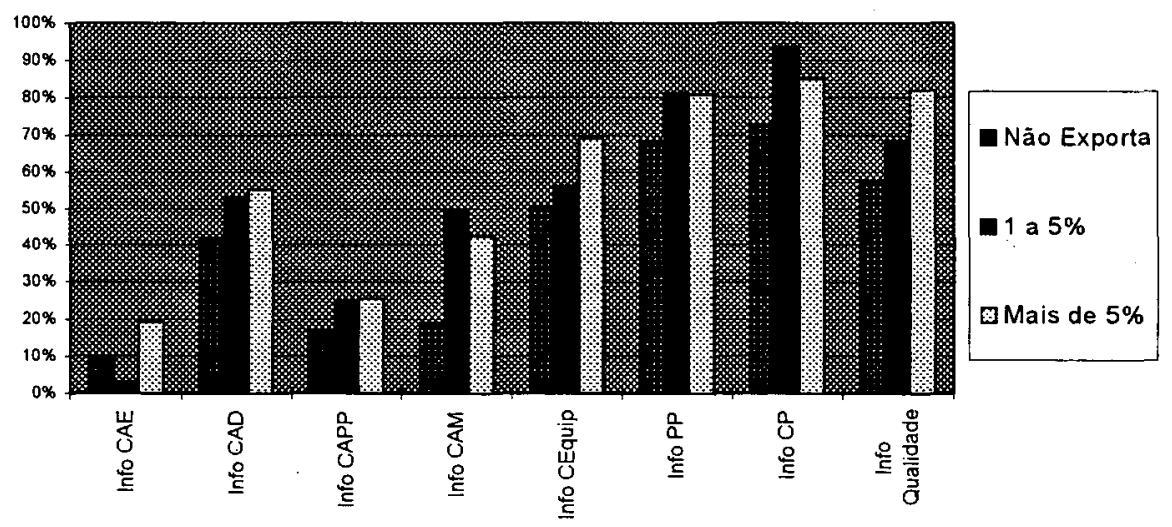

Figura 9: Incidência de automação por função por quantidade de exportação 


\section{PRODUÇÃO}

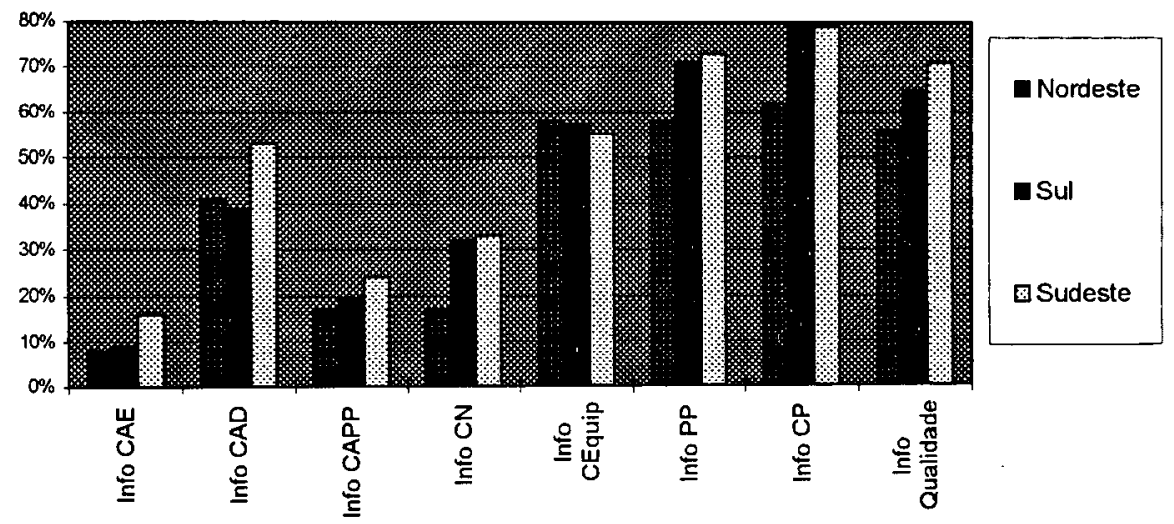

Figura 10: Incidência de automação por função por Região

O último cruzamento deste artigo é o de gêneros industriais. Consideramos aqui apenas três gêneros - mecânico, alimentos e têxtil - que estão entre os mais representativos na nossa amostra nacional e têm grandes diferenças nos seus processos de produção.

Aqui, temos um gráfico disforme (mantendo-se o núcleo), o que serve como indicativo de que certas especificidades da informatização, da automação e da integração, como esperado, estão atreladas aos setores industriais. Para aprofundar esta constatação seriam necessários estudos mais detalhados dentro de cada gênero, considerando-se cruzamentos com outras variáveis. Para que as análises por gênero possam viabilizar intervenções em empresas específicas é, no entanto,

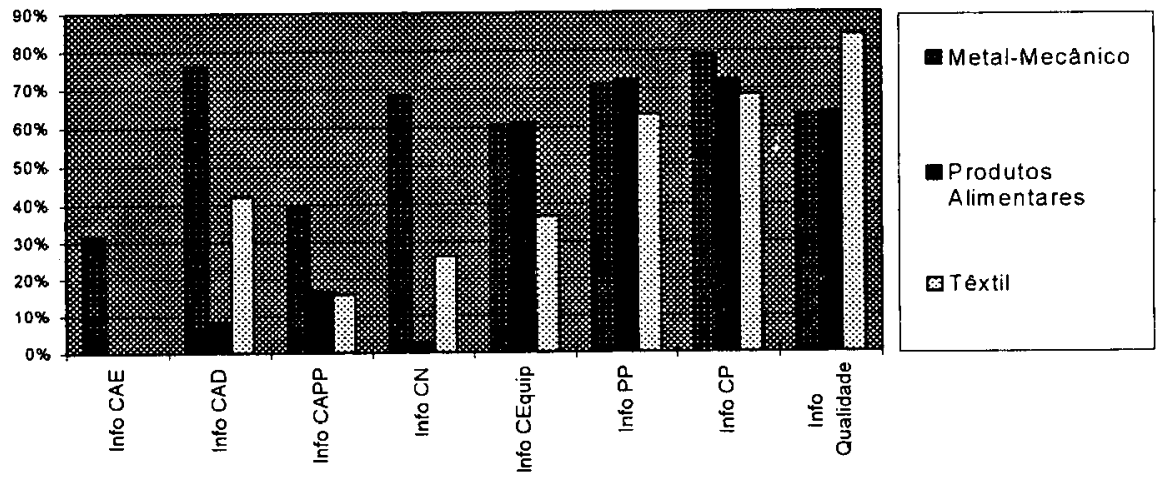

Figura 11: Incidência de automação por função por gênero industrial 
necessário que outros dados sejam agregados aos bancos: indicadores de performance, estágio internacional da técnica, modelos dos processos genéricos, entre outros. Estes pontos, por não serem objeto específico deste texto, não serão aqui enfatizados.

\section{Análise dos Resultados Encontrados}

4.1. Sobre as Perspectivas de Evolução da Indústria Nacional

O quadro de desconforto competitivo destaca a importância percebida em termos de redução de custo e melhoria da qualidade. Uma primeira leitura seria a de que as empresas estariam fundamentalmente preocupadas em aumentar a eficiência de sua operação, mantidas as características físicás do produto. Aceito, entretanto, que na prática já se opere com uma definição mais ampla de qualidade, que inclui serviços, poderse-ia entender que as empresas sentem a necessidade de melhorar sua eficiência operacional (redução de custos) mantidos/ melhorados os parâmetros de referência de seu envelope de performance produto/ serviço (qualidade do produto, entrega no prazo).

Tal entendimento poderia ser ilustrado por um gráfico bi-dimensional (Hayes e Pisano, 1992; Proença, 1994). Por uma questão de praticidade, e adotando a dicotomia proposta por Porter (1980), assumamos duas variáveis componentes de um posicionamento competitivo: custos (eficiência) e diferenciação (envelope de performance de produto/serviço). Na figura 12 , temos as curvas I e II. Tais curvas procuram delimitar uma determinada fronteira de performance para um dado nível tecnológico. Na curva $\mathrm{I}$, o ponto $\mathrm{A}$ indica que, para aquela diferenciação, incorrer-se-á naquele nível de custo. A curva II trata da situação em que uma inovação tecnológica deslocou esta fronteira: é possível, justamente, alcançar a mesma diferenciação por um custo menor. Como no ponto B.

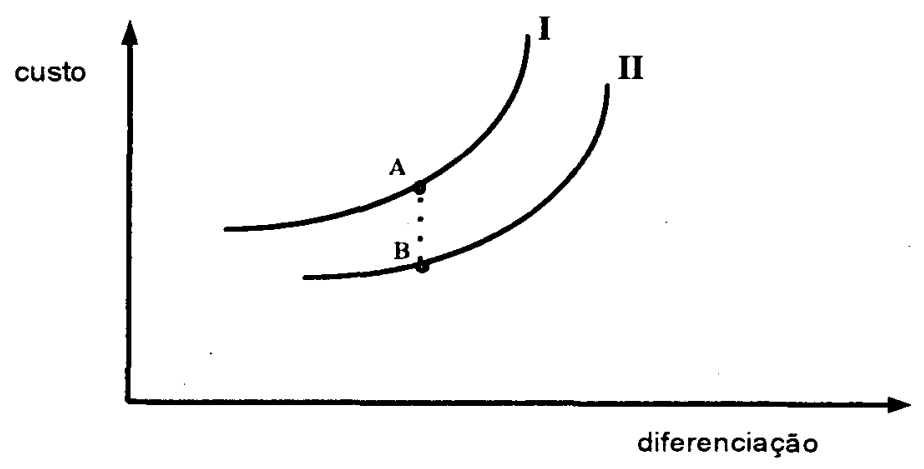

Figura 12: Custo x Diferenciação - curvas I e II 


\section{PRODUÇÃO}

O gráfico na figura 12 serve para ilustrar nosso entendimento quanto ao processo caracterizado pela introdução maciça de soluções informatizadas ao nivel do planejamento da produção e do controle da produção. Tipicamente, as empresa buscaram migrar do ponto A para o ponto $B$; isto é, aumentar sua eficiência operacional sem prejuizo ao seu envelope dado de performance produto/serviço.

O problema é que, como notávamos em texto anterior (Caulliraux e Proença, I993), em perspectiva ainda válida dada certa perda de ritmo na retomada de investimentos em produção, as empresas teriam de "ir além da defensiva". Isto é, aos avanços em gestão e organização teriam de se suceder investimentos de maior porte em tecnologia (cf. ainda Proença, 1996).

De fato, os dados colhidos na pesquisa indicam que as empresas de processos contínuos vêm investindo em controle de equipamentos, enquanto que as de processos discretos vêm reforçando sua posição em $\mathrm{CAD}$. Tais investimentos não restringem seu impacto apenas ao nivel da eficiência operacional. Uma maior automação deste tipo abre campo para ganhos em custos e em performance, simultaneamente. Esta tendência, traduzida para uma leitura em termos de posicionamento competitivo, pode ser ilustrada pela passagem da curva II para curva III, tal como na figura 13 . Nele assinalamos o leque de possibilidades de reposicionamentos viabilizados pela nova tecnologia.

O CAD, por exemplo, associado à reorganização de estruturas e processos adequados, pode comprimir o tempo de lançamento de novos produtos, abrindo campo para entradas em segmentos antes não-alcançáveis pela empresa.

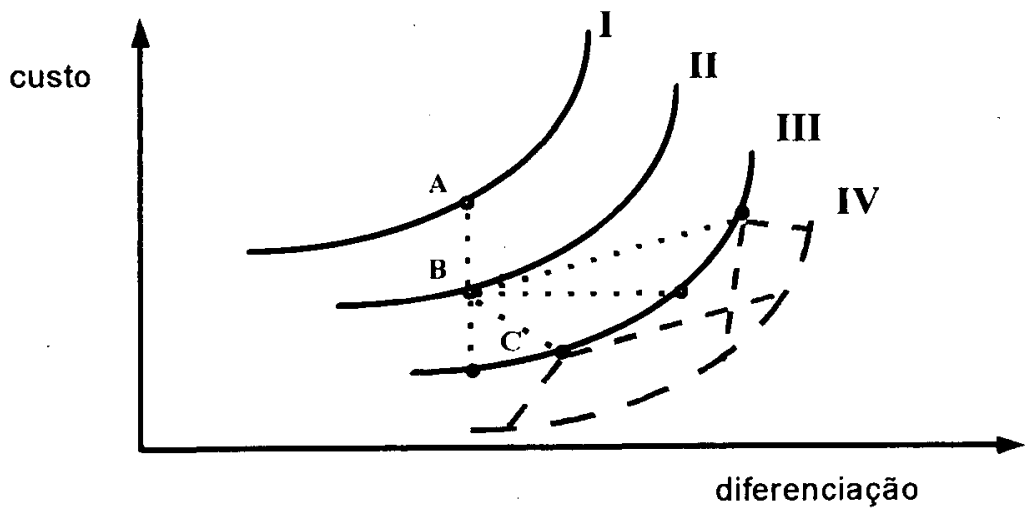

Figura 13: Custo x Diferenciação - curvas I, II, III e IV 


\section{PRODUÇÃO}

Esta passagem exige um tipo de consideração distinto da anterior. A própria aquisição de um dado software de CAD guarda implicações relativas não só ao custo de aquisição e manutenção, mas também em termos de velocidade de aprendizado e receptividade pela organização. Há que considerar ganhos em eficiência operacional, tempo em operação em sub-capacidade, impacto no sistema produtivo, distúrbios esperáveis, entre outros. Tipicamente, o movimento de II para III precisa considerar o melhor encaixe entre o posicionamento competitivo almejado e a política de informatização/automação adotada.

O problema, entretanto, é que mesmo quando esta preocupação de suporte à posição competitiva imediatamente almejada está presente, pode-se incorrer na não-consideração dos eventuais posicionamentos imaginados mais para 0 futuro. Por exemplo, suponha agora que uma firma esteja no dilema entre dois pacotes de software para $\mathrm{CAD}$. O primeiro é mais barato, mais fácil e resolve a contento seus problemas presentes, de atendimento aos segmentos de mercado com os quais a empresa opera no momento, tipicamente de pequenas empresas. O segundo é mais caro, mais dificil de aprender; mas não só resolve os problemas presentes como também é conectável ao CAD de clientes de grande porte, o melhor segmento do mercado e, portanto, prospects favoritos da área de Marketing da firma. A decisão entre um e outro tem de contemplar, portanto, o deslocamento posterior da firma, para o que na figura 13 é a curva IV.
A curva IV é o futuro, por definição incerto. O que se deve considerar, portanto, é o que Drücker (1973) chama de "a futuridade das decisões presentes". Isto é, o quanto a escolha de agora limitará/sustentará os passos futuros da empresa. Ou seja, o grau de comprometimento (Ghemawat, 1991) com uma determinada combinação de trajetória tecnológica - competitiva.

A questão aqui levantada chama atenção para o fato de que os novos investimentos em automação, para a massa das empresas da amostra, dependerão, para uma maior eficácia, de melhores conhecimentos sobre suas operações e de um melhor entendimento da prática da gestão estratégica.

\subsection{Sobre a "Qualidade" das Informatizações}

Uma análise dos softwares usados pelas empresas demonstra que para a maior parte das empresas a situação é relativamente precária. Para o "núcleo", é comum o uso de planilhas (Excel, QPro, etc) para o controle da produção ou para o controle de qualidade. Neste casos, o que se faz é uma coleta de dados manual com digitação e tratamento posterior. Para o planejamento de produção e gestão de materiais a situação típica aponta para os softwares de MRP I.

Em termos de integração informática o quadro atual, para a maior parte das empresas, é de quase ausência da mesma. Ossoftwares não trocam dados entre si, 


\section{PRODUÇÃO}

inexistem redes de chão de fábrica, inexistem bancos de dados centralizados, não são feitas modelagens dos processos, etc.

Desse modo, não devemos concluir que o relativamente elevado percentual de informatizações no "núcleo" signifique uma situação confortável ou de algum modo avançada.

\subsection{Múltiplos Caminhos, Diversas Soluções}

Mesmo pondo à parte considerações sobre o ambiente econômico e institucional no qual operam atualmente as firmas brasileiras, os resultados aqui apresentados da pesquisa Integração, a nosso ver, sugerem a ocorrência ou a iminência de movimentos de maior comprometimento estratégico por parte das empresas. Este "próximo passo" demandará, como já observado, clareza sobre o andamento e estágio de suas próprias operações, e meios conceituais e de trabalho para tomada de decisões estratégicas.

Não há, lleste momento, percursos "evidentes" para evolução de cada sistema produtivo em particular. Como se pode observar nas diversas tentativas de corte relatadas, não há evidência de um padrão específico por porte ou por região. A prática de atividade exportadora pode ser associada uma maior incidência de soluções automatizadas em um ou dois campos funcionais dentro do $\boldsymbol{Y}$, mas não chega a caracterizar padrões distintos. $O$ mesmo pode ser observado na comparação por tipos de processo de produção.

O corte efetivamente significativo se dá por gêneros, ou setores, industriais. Como visto no perfil de resultados dos setores metal-mecânico, de alimentos, e têxtil, a trajetória econômica e institucional (p.ex., politicas governamentais sobre aliquotas, importação de equipamentos, etc.), associada a suas características tecnológicas especificas, levou a quadros de incidência de soluções automatizadas bastante distintos. Este será o principal vetor de análise a ser desenvolvido em trabalhos subseqüentes.

Cabe, entretanto, tecer ainda uma outra consideração, esta derivada de resultados de nossas observações quanto à natureza da solução de automação/ informatização realmente empregada (questionário 2). Ao percorrer questionário a questionário encontramos um impressionante grau de diversidade de soluções firma-a-firma. Como constatou Caulliraux (1996), temos hoje perfis diferenciados na produção para empresas de mesmo porte, com a mesma tecnologia básica de processo, e com a mesma estratégia competitiva!

Nossa conclusão é que, tomada como um todo, a indústria está como que "experimentando" diversas alternativas, testando os percursos de sucesso/fracasso que, eventualmente, moldarão os "paradigmas" do futuro. Hoje, em plena 
transição, com as normas de competição em franca transformação, e a disponibilização de tecnologias digitais e de materiais de potencial ainda não explorados, não é possivel caracterizar a proeminência de qualquer "paradigma".

Pode-se sugerir que estamos diante do próprio momento de transição do processo dito de "equilíbrio pontuado" (punctuated equilibrium), tal como o descrito por Gould (1989) em seu livro "Vida Maravilhosa". Para Gould, ao longo dos milhões de anos de uma dada era, as espécies de vida ocupam todas as possibilidades de sobrevivência dadas por um dado ambiente - um dado eco-sistema. Então, subitamente, uma força externa um asteróide, ou a Era do Gelo - destrói tal eco-sistema, e todos os nichos que o compõem. Cabe então às espécies se "reinventarem", se lançando à experimentação para descobrirem um forma nova de sobreviver. As grandes mutações ocorreriam em "pacotes integrados", incluindo cérebro, asas, pulmões, e patas; a vida evoluiria em grandes saltos, intercalados por longos períodos de mudança incremental. E não na forma de uma crescente diversificação, mas na forma de uma miriade de experimentos, das quais a grande maioria seria dizimada, só restando uns poucos ramos bem-sucedidos.

A hipótese de Gould se presta a uma analogia irresistivel com a situação da indústria no país, e provavelmente não é original. A nosso juizo, no que concerne o processo de informatização/ automatização, o que temos até o momento são trajetórias múltiplas, conduzidas muito mais pela visão da gerência de cada empresa, do que por uma confluência generalizada em direção a uma dada solução setorial. Mesmo firmas que pretendam mimetizar a solução de referência adotada em países mais desenvolvidos esbarram nas restrições inerentes ao contexto local, e mesmo em seus próprios limites em termos de escala e escopo de produção.

Prensadas entre uma alteração ambiental tipicamente demarcada como iniciada em 1990, e particularmente após 1994, e uma oferta tecnológica vibrante e em permanente evolução, as empresas se vêem compelidas à ação. Não há como adiar a tomada de decisão quanto a como desenvolver o sistema produtivo. A própria opção por soluções de baixo comprometimento estratégico parece estar a perder fôlego. Elas simplesmente não dão conta de aportar o desempenho necessário para assegurar a sobrevivência da organização.

Pressionadas pela competição, e, por outro lado, com recursos limitados para investir, as empresas se vêem, assim, tomando decisões de forte impacto sobre seu futuro, à luz das oportunidades imediatas que descortinam a sua volta. A grande pergunta que se configura para nós está na natureza do reposicionamento estratégico posto então em curso. Tanto quanto a seu processo como quanto a seu conteúdo. Pois o que se decide agora determina fortemente qual será a indústria do Brasil do século XXI. 


\section{PRODUÇÃO}

\section{Notas}

' Ao final de julho de 1996, novas 50 empresas do estado do Ceará serão inseridas no banco de dados.

${ }^{2}$ Quando necessário, pequenos ajustes locais foram realizados.

\section{Referências bibliográficas}

CAULLIRAUX, H "Estratégias de Empresas e Modernização Industrial" in Castro, AB, Possas, ML e Proença; A (orgs.) Estratégias Empresariais na Industria Brasileira: Discutindo Mudanças, Forense Universitária, Rio de Janeiro, 1996.

CAULLIRAUX, $\mathrm{H}$ e PROENÇA, A Indo além da Defensiva, GPI/EE-COPPE/ UFRJ; mimeo, 1993.

CAULLIRAUX, H.M. e L. S. SALLES COSTA (organizadores), et al. - Manufatura Integrada por Computador - Sistemas Integrados de Produção: Estratégia, Organização, Tecnologia e Recursos Humanos, Editora Campus, Rio de Janeiro, 1995 .

DRÜCKER, P. Management: tasks, responsabilities, practices, Harper \& Row, New York, 1973.

GHEMAWAT, P. Commitment: the Dynamic of Strategy, Free Press, New York, 1991.
GOULD, S. J. Vida Maravilhosa - o acaso na evolução e a natureza da história, Ed Círculo do Livro, São Paulo, s/data. Edição original em inglês: 1989.

HAYES, R. e PISANO, G. Manufacturing Strategy: at the intersection of two paradigm shifts, Harvard Business School, mimeo, Junho, 1992.

HAYES, R. H. e S.C. WHEELW RIGHT - Restoring our Competitive Edge: Competing Through Manufacturing, John Wiley \& Sons, Nova York, 1984

KIM, J. e ARNOLD, P. Manufacturing Competence and Business Performance: a Framework and Empirical Analysis, Working Paper 91-64, OM Dept, School of Management, Boston University, November 1991.

MILLER, J. e KIM, J. 1990 Manufacturing Futures Fact Book, Research Paper Series, Manufacturing Roundtable, Boston University, 1990. 
PORTER, M. Competitive Strategy, The Free Press, New York, 1980.

PROENÇA, A Gerência de Produção e Competitividade: premissas da Abordagem por Capacitações Dinâmicas em Estratégia de Produção, Tese DSc, PEP/COPPE/UFRJ, 1994.

PROENÇA, A "A Próxima Mutação - Indústria Brasileira, TQC, e a Gerência Estratégica de Produção in Castro, $A B$, Possas, ML e Proença, A (orgs.) Estratégias Empresariais na Indústria Brasileira: Discutindo Mudanças, Forense Universitária, Rio de Janeiro, 1996.

SCHEER, A. -W. CIM, Evoluindo para a Fábrica do Futuro, Qualitymark, Rio de Janeiro, 1993. 